\title{
Editorial: Spatio-Temporal Dynamics of Metacommunities - Implications for Conservation and Management
}

\author{
Pedro Giovâni da Silva ${ }^{1 \star \dagger}$, Miguel Cañedo-Argüelles ${ }^{2 \dagger}$, Juliano André Bogoni ${ }^{3 \dagger}$ and \\ Jani Heino ${ }^{4 \dagger}$ \\ ${ }^{1}$ Programa de Pós-Graduação em Ecologia, Conservação e Manejo da Vida Silvestre, Universidade Federal de Minas \\ Gerais, Belo Horizonte, Brazil, ${ }^{2}$ Serra Húnter Fellow, FEHM-Lab, Institut de Recerca de l'Aigua (IdRA), Universitat de \\ Barcelona, Barcelona, Spain, ${ }^{3}$ Laboratório de Ecologia, Manejo e Conservação de Fauna Silvestre (LEMaC), Departamento \\ de Ciências Florestais, Escola Superior de Agricultura "Luiz de Queiroz" (ESALQ), Universidade de São Paulo (USP), \\ Piracicaba, Brazil, ${ }^{4}$ Finnish Environment Institute, Freshwater Centre, Oulu, Finland
}

Keywords: assembly mechanisms, biodiversity variation, community dynamics, conservation, ecosystem management, spatio-temporal patterns

\section{OPEN ACCESS}

Edited and reviewed by: Peter Convey,

British Antarctic Survey (BAS),

United Kingdom

${ }^{*}$ Correspondence:

Pedro Giovâni da Silva pedrogiovanidasilva@yahoo.com.br

TORCID:

Pedro Giovâni da Silva orcid.org/0000-0002-0702-9186

Miguel Cañedo-Argüelles orcid.org/0000-0003-3864-7451

Juliano André Bogoni orcid.org/0000-0002-8541-0556

Jani Heino

orcid.org/0000-0003-1235-6613

Specialty section

This article was submitted to Biogeography and Macroecology, a section of the journal Frontiers in Ecology and Evolution

Received: 20 February 2021 Accepted: 02 March 2021

Published: 31 March 2021

Citation:

da Silva PG, Cañedo-Argüelles M,

Bogoni JA and Heino J (2021)

Editorial: Spatio-Temporal Dynamics of Metacommunities - Implications for

Conservation and Management.

Front. Ecol. Evol. 9:670212.

doi: 10.3389/fevo.2021.670212

\section{Editorial on the Research Topic}

Spatio-Temporal Dynamics of Metacommunities - Implications for Conservation and Management

According to metacommunity theory (Leibold et al., 2004), the structure of local communities results from the interplay between local factors (e.g., environmental filtering, species interactions) and regional factors (e.g., dispersal rates, landscape configuration). The relative importance of these factors is highly dependent on the organisms' biological traits, landscape connectivity, and the spatial and temporal scales considered (Heino et al., 2015; Tonkin et al., 2018; Viana and Chase, 2019; Almeida-Gomes et al., 2020; Cañedo-Argüelles et al., 2020; Lansac-Tôha et al., 2021). However, the differences in metacommunity assembly mechanisms found among studies are far from being fully understood. The evaluation of temporal dynamics of metacommunities has only emerged recently (Cañedo-Argüelles et al., 2020; Jabot et al., 2020; Li et al., 2020; Lindholm et al., 2021) and the application of the metacommunity theory in other fields, such as biomonitoring, conservation biology or ecosystem restoration, is yet to be fully explored (Bengtsson, 2010; Heino, 2013; Leibold and Chase, 2018; Chase et al., 2020; Cid et al., 2020; Heino et al., 2021).

In this Research Topic, our aim was to invite researchers working in different biogeographic regions and ecological systems (Figure 1) to publish a number of innovative papers on metacommunity spatio-temporal dynamics. We expect to obtain a better understanding of how the factors and processes that structure metacommunities vary in space and time, as well as the implications of such dynamics for biodiversity conservation and ecosystem management.

\section{RELATIVE IMPORTANCE OF ENVIRONMENTAL AND SPATIAL FACTORS ON METACOMMUNITY STRUCTURE}

This Research Topic provides several examples on how the interplay of environmental and spatial factors shapes biodiversity. Czeglédi et al. evaluated the importance of the degree of urbanization, the local stream environmental conditions and the regional species pool on the community assembly of stream fishes. They found that the degree of urbanization is not a strong determinant of local stream habitat and fish community characteristics. Historical species pool and stream features shaped fish communities, with urbanization playing a rather individual role in some streams. These authors conclude that rehabilitation of urban streams should not only focus on local 


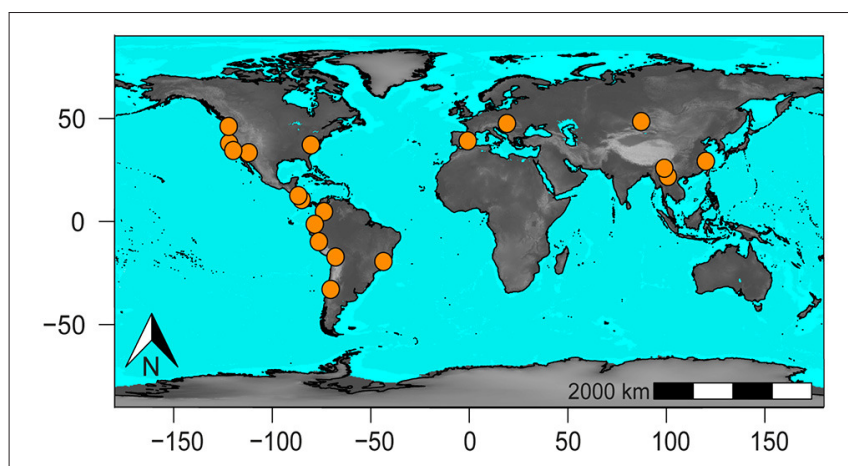

FIGURE 1 | Geographic distribution of the studies (i.e., study sites for field studies, author's affiliation for reviews) contained in the Research Topic. The background map is the elevation gradient derived from ASTER GDEM (https:// asterweb.jpl.nasa.gov/gdem.asp).

habitat improvements, but also consider how dispersal influences metacommunity organization. Kurthen et al. examined the metacommunity structure of diatoms and macroinvertebrates in river-connected and lake-connected streams. Diatoms exhibited the same metacommunity structure in both systems, while macroinvertebrates did not. Also, environmental filtering had a stronger effect on community dissimilarity in the lake-connected system than in the river-connected system for both groups. Finally, $\mathrm{He}$ et al. examined the spatial and environmental distance decay of the same organismal groups within three Chinese drainage basins. They found that environmental filtering was the strongest within the basin with the highest levels of environmental heterogeneity among sites. These findings are important because increased environmental heterogeneity may foster higher diversity of organisms in rivers and because anthropogenic impacts homogenizing the underlying abiotic template are likely to decrease aquatic biodiversity.

\section{THE IMPORTANCE OF TEMPORAL AND SPATIAL SCALES ON METACOMMUNITY STRUCTURE}

Metacommunities are shaped by environmental, spatial, and temporal processes, but their relative importance can vary with the study scale. Gálvez et al. examined variation in multiple organism groups across tropical temporary ponds. They found that environmental, spatial, and temporal processes were all important for metacommunity dynamics. However, the relative roles of these processes differed among taxa, and the environmental and spatial factors varied among sampling periods when the periods were analyzed separately. These findings indicate that a snapshot survey is not likely to reveal the dynamics of pond metacommunities, thereby hindering planning suitable conservation and management programs.

Beta diversity has played a prominent role in investigating the processes that determine the distribution patterns of communities (Anderson et al., 2011). In this Research Topic, Benito et al. evaluated the drivers of spatial and temporal beta diversity of modern and paleolimnological data of tropical South American diatoms from high elevation lakes and found different trajectories of lake diatom diversity as a response to environmental changes. These authors showed that unifying diatom ecology, metacommunity theory, and paleolimnological approaches can facilitate our understanding of the responses of tropical Andean lakes to global change effects in the near future. Nunes et al. evaluated the temporal patterns of an ant metacommunity across an elevational gradient, focusing on both taxonomic and functional facets. These authors found that taxonomic and functional temporal beta diversity did not increase with elevation. Their results indicate that at low elevations the replacement of species can cause loss of some traits, yet preserving the most common functions (nested functional communities), while at high elevations functional capabilities may change over time (replacement of traits). In the scenario of climate change, it is important to consider the role of the substitution of species on the temporal variation in functional traits of metacommunities at higher elevations.

Combining simulated metacommunities with empirical data, Castillo-Escrivà et al. investigated how temporal variations in environmental conditions and species' dispersal can affect metacommunity organization of aquatic invertebrates. According to the simulations, the importance of the temporal scale increased at high dispersal rates. However, this was not confirmed by empirical data, which showed complex spatiotemporal variations that depended on the type of organisms and ecosystems under study.

Focusing on disturbance, seasonality, multi-year climate variation, and dormancy, Holyoak et al. synthesize our current knowledge of temporal metacommunity dynamics. Although empirical studies are relatively scarce, the authors show that the four forms of temporal dynamics considered can play a significant role in metacommunity ecology and conservation planning. Since global climate change is expected to increase both the frequency and severity of different types of disturbance, metacommunities might be more frequently structured by dispersal processes in the future.

\section{APPLICATIONS IN CONSERVATION AND MANAGEMENT}

Short-term field studies have limitations to identify the underlying processes of observed patterns because both the environment and communities change through time ( $\mathrm{Li}$ et al., 2020). Record et al. provided evidence from a synthesis effort of the United States Long Term Ecological Research (LTER) program that such data can improve our ability to explain and predict biodiversity change with observational and experimental data at various spatial and temporal scales. Long-term studies that include multiple sites within a regional species pool enable a more thorough assessment of biodiversity change relative to long-term studies at a single site. Such an approach can also improve the development of metacommunity theory and its applications contributing to improved conservation efforts. 
Globally, biological invasions are a major cause of biodiversity loss (Courchamp et al., 2017, Pyšek et al., 2020). Brown and Barney argue that invasion biology is currently limited by the consideration of species in isolation (i.e., disregarding the community context), and metacommunity ecology can greatly help to overcome this barrier. The combined analysis of environmental factors and dispersal (i.e., propagule pressure) can help to assess the degree of spread of an invader. The authors show multiple parallelisms between invasion biology and metacommunity ecology that pave the way for cross-disciplinary research. Finally, the paper provides direct applications of the metacommunity theory for managing biological invasions.

\section{CONCLUDING REMARKS AND SUGGESTIONS FOR FUTURE RESEARCH}

The metacommunity perspective has clear applications in conservation and management (Bengtsson, 2010; Heino, 2013). However, metacommunity ecology and conservation biology have barely begun to be connected in an applied fashion (Leibold and Chase, 2018, Chase et al., 2020). More emphasis on the importance to understand metacommunity assembly has been given in applied contexts recently, especially in river networks (Cid et al., in press) and lakes considered as sets of interconnected systems in a landscape (Heino et al., 2021). However, terrestrial and marine ecologists have not considered metacommunity theory from this direct perspective, even though similar ideas pertaining to the importance of metapopulation dynamics (e.g., Hanski, 2005) and connectivity conservation (e.g., Ament et al., 2014) in anthropogenically affected landscapes have received considerable attention. We highlight that metacommunity structure should be studied in all realms by jointly considering environmental, spatial, and temporal dynamics, as well as anthropogenic impacts if we expect to manage and conserve biological diversity in a sustainable manner.

\section{REFERENCES}

Almeida-Gomes, M., Valente-Neto, F., Pacheco, E. O., Ganci, C. C., Leibold, M. A., Melo, A. S., et al. (2020). How does the landscape affect metacommunity structure? A quantitative review for lentic environments. Curr. Landscape Ecol. Rep. 5, 68-75. doi: 10.1007/s40823-020-0 0049-6

Ament, R., Callahan, R., McClure, M., Reuling, M., and Tabor, G. (2014). Wildlife Connectivity: Fundamentals for Conservation Action. Bozeman: Center for Large Landscape Conservation.

Anderson, M. J., Crist, T. O., Chase, J. M., Vellend, M., Inouye, B. D., Freestone, A. L., et al. (2011). Navigating the multiple meanings of beta diversity: a roadmap for the practicing ecologist. Ecol. Lett. 14, 19-28. doi: 10.1111/j.1461-0248.2010.01552.x

Bengtsson, J. (2010). "Applied (meta)community ecology: diversity and ecosystem services at the intersection of local and regional processes," in Community Ecology: Processes, Models and Applications, eds, H.A. Verhoef and P.J. Morin (Oxford: Oxford University Press), $115-130$.
In a changing world, our current understanding of the underlying drivers of biodiversity patterns and ecosystem functioning will only improve with further research jointly focusing on both spatial and temporal dynamics of metacommunities (Heino et al., 2021). Metacommunity theory (Leibold et al., 2004) should also be combined with the traditional approaches in environmental assessment (Heino, 2013) and conservation planning (Hanski, 2005) that have not paid enough attention to the dynamics of ecological communities in changing landscapes, regions, and continents so far. We suggest that there should be a paradigm shift in applied research on understanding biodiversity change and environmental degradation through the joint consideration of multiple scales and underlying metacommunity assembly mechanisms.

\section{AUTHOR CONTRIBUTIONS}

All authors listed have made a substantial, direct and intellectual contribution to the work, and approved it for publication.

\section{FUNDING}

PS thanks the Coordenação de Aperfeiçoamento de Pessoal de Nível Superior (CAPES, Code 001, PNPD program) for financial support. MC-A was supported by the Serra-Hunter programme of the Generalitat de Catalunya. JB is supported by the São Paulo Research Foundation (FAPESP) postdoctoral fellowship grants (2018-05970-1 and 2019-11901-5). JH acknowledges funding (Grant No. 331957) from the Academy of Finland for the project Global taxonomic, functional and phylogenetic diversity of stream macroinvertebrate communities.

\section{ACKNOWLEDGMENTS}

We would like to thank the peer reviewers for their valuable contributions to the improvement of the manuscripts published in this Research Topic.

Cañedo-Argüelles, M., Gutiérrez-Cánovas, C., Acosta, R., Castro-López, D., Cid, N., Fortuño, P., et al. (2020). As time goes by: 20 years of changes in the aquatic macroinvertebrate metacommunity of Mediterranean river networks. J. Biogeogr. 47, 1861-1874. doi: 10.1111/jbi.13913

Chase, J. M., Jeliazkov, A., Ladouceur, E., and Viana, D. S. (2020). Biodiversity conservation through the lens of metacommunity ecology. Ann. N. Y. Acad. Sci. 1469, 86-104. doi: 10.1111/nyas.14378

Cid, N., Bonada, N., Heino, J., Cañedo-Argüelles, M., Crabot, J., Sarremejane, R., et al. (2020). A metacommunity approach to improve biological assessments in highly dynamic freshwater ecosystems. Bioscience 70, 427-438. doi: 10.1093/biosci/biaa033

Cid, N., Eros, T., Heino, J., Singer, G., Jähnig, S., Cañedo-Argüelles, M., et al. (in press). From meta-system theory to the sustainable management of rivers in the Anthropocene. Front. Ecol. Environ.

Courchamp, F., Fournier, A., Bellard, C., Bertelsmeier, C., Bonnaud, E., Jeschke, J. M., et al. (2017). Invasion biology: specific problems and possible solutions. Trends Ecol. Evol. 32, 13-22. doi: 10.1016/j.tree.2016.11.001

Hanski, I. (2005). The Shrinking World: Ecological Consequences of Habitat Loss. Oldendorf: International Ecology Institute. 
Heino, J. (2013). The importance of metacommunity ecology for environmental assessment research in the freshwater realm. Biol. Rev. 88, 166-178. doi: 10.1111/j.1469-185X.2012.00244.x

Heino, J., Alahuhta, J., Bini, L. M., Cai, Y., Heiskanen, A.-S., Hellsten, S., et al. (2021). Lakes in the era of global change: moving beyond single-lake thinking in maintaining biodiversity and ecosystem services. Biol. Rev. 96, 89-106. doi: $10.1111 /$ brv.12647

Heino, J., Melo, A. S., Siqueira, T., Soininen, J., Valanko, S., and Bini, L. M. (2015). Metacommunity organisation, spatial extent and dispersal in aquatic systems: patterns, processes and prospects. Freshwater Biol. 60, 845-869. doi: $10.1111 /$ fwb. 12533

Jabot, F., Laroche, F., Massol, F., Arthaud, F., Crabot, J., Dubart, M., et al. (2020). Assessing metacommunity processes through signatures in spatiotemporal turnover of community composition. Ecol. Lett. 23, 1330-1339. doi: 10.1111 /ele. 13523

Lansac-Tôha, F. M., Bini, L. M., Heino, J., Meira, B. R., Segovia, B. T., Pavanelli, C. S., et al. (2021). Scale-dependent patterns of metacommunity structuring in aquatic organisms across floodplain systems. J. Biogeogr. doi: 10.1111/jbi.14044. [Epub ahead of print].

Leibold, M. A., and Chase, J. M. (2018). Metacommunity Ecology. Princeton: Princeton University Press.

Leibold, M. A., Holyoak, M., Mouquet, N., Amarasekare, P., Chase, J. M., Hoopes, M. F., et al. (2004). The metacommunity concept: a framework for multi-scale community ecology. Ecol. Lett. 7, 601-613. doi: 10.1111/j.1461-0248.2004.00608.x

Li, Z., Xing, Y., Liu, Z., Chen, X., Jiang, X., Xie, Z., et al. (2020). Seasonal changes in metacommunity assembly mechanisms of benthic macroinvertebrates in a subtropical river basin. Sci. Total. Environ. 729:139046 doi: 10.1016/j.scitotenv.2020.139046

Lindholm, M., Alahuhta, J., Heino, J., and Toivonen, H. (2021). Temporal beta diversity of lake plants is determined by concomitant changes in environmental factors across decades. J. Ecol. 109, 819-832. doi: 10.1111/1365-2745.13508

Pyšek, P., Hulme, P. E., Simberloff, D., Bacher, S., Blackburn, T. M., Carlton, J. T., et al. (2020). Scientists' warning on invasive alien species. Biol. Rev. 95, 1511-1534. doi: 10.1111/brv.12627

Tonkin, J. D., Altermatt, F., Finn, D. S., Heino, J., Olden, J. D., Pauls, S. U., et al. (2018). The role of dispersal in river network metacommunities: patterns, processes, and pathways. Freshwater Biol. 63, 141-163. doi: 10.1111/fwb. 13037

Viana, D. S., and Chase, J. M. (2019). Spatial scale modulates the inference of metacommunity assembly processes. Ecology 100:e02576. doi: 10.1002/ecy.2576

Conflict of Interest: The authors declare that the research was conducted in the absence of any commercial or financial relationships that could be construed as a potential conflict of interest.

Copyright (C) 2021 da Silva, Cañedo-Argüelles, Bogoni and Heino. This is an openaccess article distributed under the terms of the Creative Commons Attribution License (CC BY). The use, distribution or reproduction in other forums is permitted, provided the original author(s) and the copyright owner(s) are credited and that the original publication in this journal is cited, in accordance with accepted academic practice. No use, distribution or reproduction is permitted which does not comply with these terms. 